\title{
Comments on the XIV International HIV/AIDS Conference: An 'Ubuntu' Perspective
}

\author{
Fhumulani Mavis Mulaudzi \\ School of Nursing, University of Northwest, Private Bag X 6001, \\ Potchefstroom 2520, Republic of South Africa \\ 20877749@nwu.ac.za
}

\begin{abstract}
The statistical reports as shown by the Joint United Nations programme on HIV/AIDS (UNAIDS) indicate that despite efforts to combat the epidemic, the number of new infections continues to rise daily. This paper reflects on resolutions taken during the XIV International HIV/AIDS Conference in an attempt to link them with the role that the African continent may play in the fight against HIV/AIDS. The principles of 'ubuntu', such as sharing of opportunities, responsibilities and challenges, participatory decision making and leadership, and reconciliation as a goal of conflict management, are used as the point of departure in assessing a range of key issues debated in the Conference.
\end{abstract}

\section{Keywords}

epidemic, Ubuntu, UNAIDS, leadership, reconciliation

\section{Introduction}

The XIV International Conference on HIV/AIDS organized by the Joint United Nations Programme on AIDS (UNAIDS) and its affiliate organizations was held in Toronto, Canada, August 2006. Here I reflect on the deliberations of the conference using the African motif of 'ubuntu'.

Elias Bongmba has argued that UNAIDS serves as a 'new symbol of international compassion because it is dedicated to providing "leadership and advocacy, strategic information, tracking, monitoring and evaluation of the epidemic and responses to it, civil society engagement and partnership development; mobilization of resources to support effective response".'

\footnotetext{
1 Elias K. Bongmba, Facing a Pandemic: The African Church and HIVIAIDS Crisis, forthcoming (Waco, Texas: Baylor University Press, 2007).
} 
Bongmba argues that UNAIDS' major contribution to the fight against the disease is organizing the international AIDS conference which brings together 'AIDS activists, physicians, researchers, and policy makers who have shared critical information at these meetings.' The first conference was held in Atlanta, Georgia on April 15-17, 1985; the second in Paris, June 23-25, 1986. Subsequent conferences were held in Stockholm, Sweden (1988), Montreal, Canada (1989), Durban, South Africa (2000), and in Bangkok, Thailand (2004) where the attendees focused on access to treatment.

Speaking to the theme of the Toronto Conference, 'Time to Deliver', Executive Director of UNAIDS, Dr Peter Piot, noted that:

...this conference comes out at a special time because it is clear that we are for the first time seeing results... It is time now that we move from crisis management to long term sustainable results and that we start thinking of the response to AIDS in decades, in generations perhaps and not one year to another. $^{2}$

In his closing address Dr Wainberg said:

... this conference cannot be deemed a success unless we collectively realize our theme of 'Time to Deliver'. Indeed we will have failed unless we dramatically and rapidly expand by millions the numbers of people around the world with access to antiretroviral drugs and simultaneous scale up prevention. Progress cannot be achieved if more people become infected by HIV each year than the numbers that are unable to access treatment. ${ }^{3}$

The conference featured more than 4,500 presentations and an array of community and cultural activities. Over 26,000 participants from more than 170 countries attended the conference, representing a variety of backgrounds, for example, scientists, clinicians, policymakers, people living with HIV/AIDS (PLWHA), community leaders, religious leaders, traditional healers and caregivers. In the spirit of sharing, the majority of participants received sponsorships to attend the conference.

At the conference it was noted that, according to UNAIDS, an estimated 39 million people are living with HIV/AIDS world-wide, the majority of them in developing countries. In 2005, an estimated 4.1 million people were newly infected with the virus while 2.8 million died of AIDS-related illnesses; only 24 percent of 6.8 million people living with HIV/AIDS in low and

2 Peter Piot, '25 Years of HIV/AIDS Reflecting Back and Looking Forward,' (paper presented at the XIV International HIV/AIDS Conference, August 2006, Toronto, Canada), <www. aids2006.org> 28/02/2007.

${ }^{3}$ M. Wainberg, 'Closing Address,' (paper presented at the XIV International HIV/AIDS Conference, August 2006, Toronto, Canada), <www.aids2006.org/admin/images/upload/1242. pdfs 21/02/2007. 
middle income countries who need antiretrovirals have access to treatment; just 8 to 13 percent of 800,000 children under 15 in need of HIV treatment have access; and fewer than one in five (4-16\%) of people at high risk for infection have access to effective prevention. The data is disturbing and it shows that there is still a lot to be done to combat HIV/AIDS, especially in developing countries.

There was evidence at the conference of a growing commitment to fight the epidemic, as seen in Millennium Development Goal number six, which contains a commitment to reduce HIV/AIDS by the year 2015. Moreover, we know that the $\mathrm{G} 8$ leaders committed themselves to achieve universal access to prevention, care, treatment and support by 2010 , a goal subsequently adopted by the UNAIDS and he World Health Organization. A variety of well-funded seminars, workshops and conferences have been held globally to discuss issues pertaining to HIV and AIDS, and numerous policies have been annunciated and pledges made by politicians, the business sector, religious leaders, traditional leaders, academics and people at grass roots levels all over the world.

Given the prominence of HIV and AIDS in Africa, one may ask what the continent is doing about the epidemic? What programmes exist specifically to reach the targets set for 2015 in the Millennium Development Goals? While the United Nations assists all nations in the fight against HIV/AIDS, African nations still need to take responsibility for their own strategies to combat the disease in ways that are applicable to the African context.

To ask for an African perspective on mechanisms to deal with HIV/AIDS is to suggest that strategies based on a 'one size fits all' approach are unacceptable. Policies formulated elsewhere sometimes give rise to skepticism and fear. For example, pressure to use antiretroviral drugs may be associated with agendas of big pharmaceutical companies to access profitable markets or influence economies.

\section{Ubuntu and Resolutions of the International HIV/AIDS Conference}

My argument is that African countries participating in a global alliance against HIV/AIDS must still find ways of developing African solutions for African problems. At this point, I turn to the idea of 'ubuntu' as a point of departure in reflecting on the UNAIDS conference, because it provides a moral strategy for understanding and promoting the global fight against HIV/AIDS. Mbigi and Maree regard ubuntu as:

... a figure of speech that describes the importance of group solidarity on issues that were pivotal to the survival of the African communities, who as a 
consequence of poverty and deprivation have to survive through group care and not individual reliance. ${ }^{4}$

Possible English translations of ubuntu include 'humanity towards others', 'I am because we are', 'a person becomes human through other persons', and 'a person is a person because of other persons'. This intrinsic relational principle is quintessentially African. Asked what this might mean practically, I would say that it includes, to give some examples, such principles as helping one another by making sure that one does not eat while one's neighbour is hungry; sharing opportunities, responsibilities and challenges; participatory decision making and leadership; and reconciliation as a goal of conflicr management. ${ }^{5}$

Based on the emphasis by Mbigi and Maree on solidarity and cohesiveness as key to combating the HIV/AIDS pandemic, ${ }^{6}$ I would regard ubuntu to be a driving force behind the gathering of the global AIDS community in biannual meetings to share and discuss issues related to the pandemic. This is how I now seek to interpret the main issues discussed at the recent XVI International AIDS Conference in Toronto.

\section{The Main Issues Discussed During the Conference}

The conference had several tracks, for example, social, behavioral and economic science, leadership, epidemiology, prevention and prevention research, clinical research, treatment and care, policy and immunity. There were also special programmes such as those focused on community, youth and grandmothers. The key challenges in response to the disease were highlighted and discussed in detail.

The answer to these key challenges lies in the principle of collectivism. At the Toronto meeting it was clear to observers that the international community wanted to come to terms with the view that it is necessary to make decision-making participatory, specifically to underscore the importance of people and relationships over things. In that light I touch on selected themes.

${ }^{4}$ L. Mbigi and J. Maree, Ubuntu: The Spirit of African Transformational Management, (Randburg, South Africa: Knowledge Resources, 1995).

5 D. Louw, An African Assessment of Religious Other, <www.bu.edu/wcp/Papers/Afri/ AfriLouw.htm> 28/02/2007.

${ }^{6}$ Mbigi and Maree, Ubuntu. 


\subsection{Research}

The fight against HIV/AIDS is challenging because it also requires research on all fronts. Unsurprisingly, many scholars who presented their research at the conference made a call to accelerate research to end the epidemic. Research will be successful in Africa if the methodologies used consider principles of solidarity and collectivism and the inclusion of the participants. If they do not become inclusive of different cultural point of views, research programmes could be seen as mechanisms imposed from outside African communities. Interpretive and critical theory approaches, which are planned by and with the participants, would go a long way in enhancing not only the quality of research, but could yield results that would be implemented easily because different communities have participated in the process.

Another critical issue relates to the funding of research. The Bill and Melinda Gates Foundation made a commitment to continue supporting and funding microbicides research, which can assist in preventing the spread of the virus. But how viable will such initiatives be in an African context where a woman is still in a subordinate position? Will a woman be able to negotiate the use of microbicides? If used without the husband's knowledge, will it affect relationships and lead to divorce? Will it be ethically right to ask people to deceive their partners? How long will the effect of the microbicides last? Will a woman be able increase the dose? If so when? The questions arise because many women in an African context still find it difficult to exercise their rights, let alone to discuss issues pertaining to sex or negotiate safe sex.

The new focus of much attention was research on male circumcision, with studies showing that male circumcision reduces the spread of HIV/AIDS. Male circumcision is an indigenous practice that is practiced by many tribes in the African context, though not all. The question is: will indigenous methods of circumcision be supported or will the practice be commercialized? Will there be participatory engagement on the issue, as emphasized in ubuntu, with indigenous leaders, to find ways of incorporating their practices, and to ensure that further research is done on ways of merging indigenous methods and modern ways?

\subsection{Health and Human Resources}

The importance of human resources in the fight against the pandemic was also discussed during the Toronto Conference. Participants highlighted a gross shortage of human resources needed for the fight against the pandemic, 
especially in developing countries. The developing world is experiencing a massive haemorrhage of its health care workers as they emigrate to developed countries, due in part to increased workloads caused by HIV/AIDS. The epidemic is also affecting the intake of health professionals, and has changed the way young people view health work, making it a less desirable career choice and leading to a lack of health workers trained to prevent and treat AIDS.

This reality contradicts the ubuntu principle, which negates individualism and promotes solidarity. Ubuntu emphasizes caring, compassion, warmth, understanding, sharing, and humanness. All these are aspects that are addressed and emphasized in the pledges and caring ethos of health care workers. But they are undermined when circumstances push health care workers to think about the issue of money and working conditions rather than the care and plight of their own people. Thus, the values ubuntu embodies are undermined in Africa. If we accept that charity begins at home, then we might point to a principle of patriotism that emphasizes sacrifice for one's group - often lacking notwithstanding the many health care workers who continue to uphold the spirit of ubuntu by working hard despite shortages of staff and material resources, and long hours coupled with low salaries.

Presentations were made at the conference on the importance of training of community based workers. Some stressed that governments and nongovernmental organizations could play a crucial role in providing this training. Their role should not only be to set up training sites but also to strengthen the monitoring and evaluation strategies to ensure the success of the training so that participants would use the knowledge to enhance and work to sustain community based care. Such an endeavor could go a long way in assisting and alleviating staff shortages. In addition to training, presenters argued, steps should be taken to improve the salaries and working conditions of health care professionals in developing countries so that they will not be attracted to higher salaries ourside their countries and regions.

This matches the WHO's programme to 'Treat, Train, Retain' to confront this crisis, to be implemented under the umbrella of the Global Health Workforce Alliance established in May 2006, ${ }^{7}$ a partnership of governments, aid agencies, civil sociery groups and multilateral organizations. By increasing the number of well-trained, healthy and motivared health workers, the plan significantly benefit health systems.

\footnotetext{
${ }^{7}$ See $<$ www.who.int/mediacentre/news/releases/2006/pr37/en/index.html>.
} 


\subsection{Youth Programme}

The inclusion of a youth programme also marked the XIV HIV/AIDS International Conference and raised the issue of participatory decision-making and leadership. Statistics show that half of all new HIV infections are among young people under the age of 25 years. ${ }^{8}$ During the opening ceremony Frika Iskander, a 24 year old from Indonesia, said: 'I am representing the new face of AIDS a young Asian woman.' She recounted and emphasized the stigma and discrimination still attached to HIV/AIDS. Ironically one would think that after 25 years people have started accepting that the disease can affect anyone whatever their status, yet people living with HIV/AIDS continue to suffer from discrimination. Perhaps we need the biblical strategy of 'do unto others what you would like them to do unto you', something faith based organizations can promote in national and international strategies to combat the epidemic. ${ }^{9}$

Iskander also made a call to involve the youth in all programmes to combat the spread of the pandemic. In their deliberations the youth pointed out that they feel marginalized as they are never involved in the decision-making and policy-making of HIV/AIDS, while politicians, researchers, scientists and policy makers debate issues and formulate policies and strategies for the youth without consulting them.

\subsection{The Role of People Living with HIVIAIDS}

For many people who have observed the UNAIDS conferences, it was gratifying to see delegates focus at length on the challenge to intensify the involvement of affected individuals and the communities. There was a growing consensus among the participants that the inclusion of people living with and affected by HIV would be an important way of putring the plight of the infected and the affected in perspective. In addition to people living with HIV/AIDS and the many families and friends who are affected by HIV/AIDS, presenters also discussed and encouraged the idea that marginalized communities should be incorporated into the struggle and fight against the disease.

\footnotetext{
${ }^{8}$ See <www.actoronto.org/website/home.nsf/pages/hivaidsstatsyouth> 20/03/2007.

9 The faith based organisations had workshops at the Conference on their role in combating the pandemic. In conclusion they pledged commitment to assist in the fight against HIVAIDS, reiterating their advantage over government or business in having a vast following that constitures the biggest pool of volunteers. See R. Warren, 'Rick and Kay Warren Challenge Church Leaders,' <www.canadianchristianity.com/cgi-bin/na.cgi?nationalupdates/060817aids> 28/02/07.
} 
One such marginalized group is that of children and orphans. According to the United Nations Children's Fund (UNICEF) there are 15 million Aids orphans worldwide. ${ }^{10}$ Participants at the conference discussed the growing orphan crisis, especially in Africa, highlighting the importance of sharing and collectively owning responsibilities while placing people and relationships above things.

Child headed families have become the order of the day. The older siblings are faced with the problems that should be faced by adults. In turn, grandmothers are faced with the responsibility of taking care of orphans. Chintu and Mwinga put it clearly, saying:

In homes where both parents have succumbed to the infecrion, children either fend for themselves or are under the care of grandparents who are past the age of economic productivity. With little opportunity to acquire basic education or to develop job skills, orphans often take to the streets to fend for themselves a situation that leaves them engaging in activities that expose them to disease. AIDS orphanages are new to Africa because the epidemic has affected the ability of families to care for orphans within the extended family. ${ }^{11}$

Of significance here is the Grandmothers' Network funded and initiated by Stephen Lewis. The organization has branches globally. It gives grandmothers taking care of orphans the opportunities to share their sad stories. In African culture, it is often taken for granted that you bear children to take care of you during old age, but the HIV epidemic has changed the status quo. Grandparents share their stories of loss and the anticipated future of taking care of their granddaughters/sons during the times that they themselves need care. They also indicated the emotional drain that the task of caring causes due to the generation gap.

Looking at it from an African perspective, where extended families are normative, one may say the introduction of nuclear families contributes to increasing the burden of HIV/AIDS. Contrary to past traditions, when parents die there is no-one familiar to care for the children, and if taken to a grandmother, they are not used to them. Moreover, because the English language takes precedent over the mother tongue in many African countries, language becomes a problem. Added to the problem of loss and change of lifestyle, children and grandparents find themselves faced with communication breakdown problems, thus making it difficult for the grandparents to cope.

10 UNAIDS, UNICEF and USAID. 'Children on the Brink,' (USAID, 2004). See <www. unicef.org/publications/index_22212.html> 20/02/2007.

11 F. R. Chintu and A. Mwinga, 'An African Perspective on the Threat of TBA HIV/AIDS Can Despair be Turned into Hope?' The Lancet 353, no. 9157 (March 1999): 997. 
And what happens when today's grandmothers die? Will governments' social services cope? How will we sustain solidarity and cohesiveness among families?

\subsection{Human Rights}

Respect for human rights was also raised at the Conference, discussed in the context of access to treatment. It was evident that most activists and researchers consider the lack of treatment in many countries to be a gross violation of the human rights of the individuals who are infected with the virus. It was also evident that there is lack of political commitment on issues of universal access.

As in previous conferences, women's rights groups were also present and raised issues pertinent and relevant to the abuse of women. What came out strongly was the issue of power imbalance. It remained clear that women who depend on their husbands for financial support are powerless and cannot always negotiate safe sex for fear of rejection which may lead to divorce. Problems such as rape, sex trade, women abuse and social ostracism are still rife. Women called for women's self-empowerment and that they be assisted with microfinancing. They also reiterated that efforts to address violence and women abuse be intensified and that there be mechanisms to rebuild the lives impacted by violence.

Human rights activists also emphasized the need for equality and respect for those living with HIV/AIDS. The stalling of the South African government in providing treatment on grounds that HIV drugs were toxic was roundly condemned. A contradiction here, though, was that some presenters used media that showed faces of HIV/AIDS research subjects, threatening their privacy and anonymity and perhaps increasing their vulnerability. It can be argued that the nature of the disease and the desperation for a cure may subject participants to abuse by researchers.

\subsection{Abstain, Be Faithful and Condomise}

The $\mathrm{ABC}$ model as a prevention strategy was debated at length. It was shown that the strategy is not working in most countries as a result of issues of religion and culture, besides impinging on the issue of morality. Questions were raised about promoting condom use versus abstinence.

In Muslim communities and other African countries where polyandry is practiced, the message of 'be faithful and stick to one partner' is not well received. Gausset argues that it is not monogamy or polygamy that fuels the spread of HIV/AIDS, and that the 'be faithful' principle can still be practiced 
in a polygamous relationship. ${ }^{2}$ This raises the issue of the principle of participatory decision-making. It is critical that people at the grassroots level be consulted when formulating policies that affect them.

The issue of gender inequality and negotiation of condom use has also become a major problem in societies where women are in subordinate position. Presenters called for states and governments to empower women to negotiate issues that deal with their sexuality. In his closing statement the United Nations Envoy for AIDS in Africa and former Canadian ambassador to the UN, Stephen Lewis, said:

I challenge you my fellow delegates to enter the fray of gender inequality. There is no more honourable and productive calling. There is nothing of greater import in this world. All roads lead from women to social change, and that includes subduing the pandemic. ${ }^{13}$

These issues highlight the need to employ the principle of ubuntu as a point of departure when addressing HIV/AIDS issues.

\section{Conclusion}

In conclusion, one may say that the issue of empowerment and integration of modern and indigenous practices must be at the forefront of our fight against the pandemic. Research that does not take into account issues of culture and religion will not succeed. Most importantly, let us listen to the lived experience of those infected and affected.

More money will be required to fund research programs for vaccines and preventive gels, which empower women to control their vulnerability to the infection. More drugs will be needed at affordable prices for AIDS patients. In the context of Africa, donors should be more supportive of national priorities set by Africans themselves and not push projects that do not coincide with a country's needs. International donors need to learn more about Africa and the African context of HIV/AIDS and adapt their programs to local circumstances, which vary greatly from country to country. Treatment needs to be provided for children infected and affected with HIV/AIDS, along with community care for AIDS orphans. Above all, people living with HIV/AIDS need to be accepted by society and not marginalized or stigmatized.

${ }^{12}$ Q. Gausset, 'AIDS and Cultural Practices in Africa: The Case of Tonga (Zambia), Journal of Social Science and Medicine, no. 52 (2001): 509-518.

${ }^{13}$ Steven Lewis, 'Closing Address,' (paper presented at XIV International HIVIAIDS Conference, July 2006, Toronto, Canada), <www.aids2006.org > 21/02/2007. 
Two years hence, there will be another AIDS Conference in Mexico. It is hoped that by then, the world will have moved closer towards reaching its goal for reducing the number of new infections and increasing the number of those who are able to access treatment and care. Africa must equip itself to take charge of its own problems. Wake up Africa the ball is in your court.

\section{Bibliography}

ACTA (AIDS committee of Toronto HIV/AIDS). HIVIAIDS Statistics Youth. <www.actoronto. org/website/home.nsf/pages/hivaidsstatsyouth> 28/02/2007.

Bongmba, Elias K. Facing a Pandemic: The African Church and HIVIAIDS Crisis. Waco, Texas: Baylor University Press, 2007, forthcoming.

Chintu, F. R. C. P. and Mwinga, A. 'An African Perspective on the Threat of TBA HIV/ AIDS - Can Despair be Turned into Hope?' The Lancet 353, no.9157 (March 1999): 997.

Gausset, Q. AIDS and Cultural Practices in Africa: The Case of Tonga (Zambia). Journal of Social Science and Medicine. 52 (2001): 509-518.

Imhof, F. 'Rethinking Values that Shape Morality.' <www.ecumenicaladvocacyalliance.ch/> 28/02/2007.

Louw, D. 'An African Assessment of Religious Other.' <www.bu.edu/wcp/Papers/Afri/AfriLouw. htm> 28/02/2007.

Lewis, S. 'Closing Address.' Conference paper, XIV International HIVIAIDS Conference, July 2006, Toronto, Canada, <www.aids2006.org > 21/02/2007.

Malunga, C. 'Learning Leadership Development from African Cultures: A Personal Perspective.' INTRAC Praxis Note 25 (2006).

Mbigi, L. and Maree, J. Ubuntu: The Spirit of African Transformational Management, Randburg, South Africa: Knowledge Resources, 1995.

National Alliance of State and Territorial Directors (NASTAD ). 'A Turning Point: Confronting HIV/AIDS in African American Communities.' NASTAD, 2005 <www.nastad.org/Docs/ highlight/2006113_AA_Call2Action_120905_final.pdf > 27/02/2007.

Piot, P. '25 Years of HIV/AIDS: Reflecting Back and Looking Forward.' Conference paper, XIV International HIVIAIDS Conference, August 2006, Toronto, Canada, <www.aids2006.org> 28/02/2007.

Tobias, Randall L. 'Remarks for Conference.' Conference Paper, AIDS in Africa: A Perspective from African Mothers, March 13, 2006, Washington, D.C. <http://www.state.gov/s/gac/rl/ $\mathrm{rm} / 2006 / 63028$.htm $>21 / 02 / 2007$.

Warren, R. 'Rick and Kay Warren Challenge Church Leaders.' <www.canadianchristianity.com/ cgi-bin/na.cgi?nationalupdates/060817aids> 28/02/07.

Wainberg, M. 'Closing Address.' Conference paper, XIV International HIVIAIDS Conference, August 2006, Toronto, Canada, <www.aids2006.org> 21/02/2007. 